\title{
Keterampilan Proses Sains Mahasiswa Pendidikan Fisika STKIP Nurul Huda pada Mata Kuliah Optika
}

\author{
Effendi ${ }^{1 *}$, Arini Rosa Sinensis ${ }^{2}$, Widayanti ${ }^{3}$ dan Thoha Firdaus ${ }^{4}$ \\ 1,2,3,4 Prodi Pendidikan Fisika STKIP Nurul Huda \\ Jl. Kotabaru, Desa Sukaraja, Kec. Buay Madang, Kab. OKU Timur \\ *E-mail: effendi@stkipnurulhuda.ac.id
}

\begin{abstract}
Abstrak
Penelitian ini bertujuan untuk mendeskripsikan Keterampilan Proses Sains (KPS) Mahasiswa Program Studi Pendidikan Fisika pada Mata Kuliah Optika. Penelitian ini menggunakan metode deskriptif. KPS yang dianalisis terdiri dari 9 indikator meliputi mengamati, mengklarifikasi, menafsirkan data, memprediksi, berhipotesis, menganalisis, merencanakan, percobaan/penelitian, menggunakan alat dan bahan, menerapkan konsep dan mengkomunikasikan. Hasil penelitian menunjukkan bahwa Keterampilan Proses Sains secara keseluruhan memperoleh nilai rata-rata persentase $84,10 \%$ dengan kategori sangat baik. Dengan demikian sangat jelas bahwa KPS mahasiswa Pendidikan fisika STKIP Nurul Huda memiliki keterampilan yang sangat baik sehingga memberikan efek yang positif terhadap perkembangan pola berpikir dan sikap mahasiswa yang pada akhirnya akan berdampak pada keberhasilan mahasiswa dalam belajar.
\end{abstract}

Kata kunci: Keterampilan Proses Sains, Optika, dan Pendidikan Fisika

\begin{abstract}
This study aims to determine the Science Process Skills (KPS) of Physics Education Study Program Students in the Optics Subject. This research uses a descriptive method. The analyzed consists of 9 indicators including observing, clarifying, interpreting data, predicting, hypothesizing, analyzing, planning, experimenting / researching, using tools and materials, applying concepts and communicating. The results showed that the Science Process Skills as a whole obtained an average score of $84.10 \%$ in the very good category. Thus it is very clear that KPS Physics Education student STKIP Nurul Huda has excellent skills so that it has a positive effect on the development of student thinking patterns and attitudes which will ultimately have an impact on student success in learning..
\end{abstract}

Keywords: Science Process Skill, Optic, and Physic Education

\section{PENDAHULUAN}

Proses ilmiah yang dilakukan pada pembelajaran salah satunya Keterampilan Proses Sains (KPS). KPS suatu pendekatan yang mengarahkan siswa untuk menemukan pengetahuan melalui eksperimen sains (Artayasa et al., 2017). Karena sains dapat membangun keterampilan proses dan produk sains. Sains dan hasil belajar memiliki integrasi yang sangat erat dalam pembelajaran tingkat rendah hingga Pendidikan tinggi. Sains pada jenjang Pendidikan tinggi dipelajari melalui mata kuliah dasar salah satunya fisika dasar (Widayanti et al., 2018).
Mata kuliah fisika dasar 2 mata kuliah wajib disajikan semeter 2 Program Studi Pendidikan Fisika di STKIP Nurul Huda. Dalam kurikulum yang berlaku mata kuliah Fisika dasar ini akan termasuk mata kuliah wajib yang harus diambil dan diselesaikan. Sebab itu mahasiswa perlu memaksimalkan proses dalam perkuliahannya, terutama berkaitan dengan keterampilan di dalamnya.

Pembelajaran sains idealnya memberikan pengalaman secara langsung sehingga calon guru fisika dapat mengembangkan KPS (Hasyim, 2018). Mengingat akan pentingnya akan hal tersebut KPS yang dimiliki oleh mahasiswa diharapkan dapat menemukan pengetahuannya sendiri, 
baik kegiatan perkuliahan di dalam kelas maupun kegiatan di luar kelas (Hadiya, 2018).

KPS ini penting untuk dikuasai oleh mahasiswa fisika (Darmaji et al., 2018). Pada jenjang perkuliahan Mahasiswa pendidikan fisika sudah seharusnya memiliki KPS karena sebagai calon guru fisika dituntut harus mampu merancang sebuah metode ilmiah yaitu eksperimen/percobaan fisika dan melaksanakannya dengan cara yang tepat (Firdaus \& Sinensis, 2017). KPS bukan hanya hal yang praktis didapatkan, akan tetapi diperoleh dari pembiasaan-pembiasaan yang sering dilakukan dalam kegiatan pembelajaran dan kehidupan sehari-hari. Sesuai dengan data yang ada di Biro Administrasi dan Kemahasiswaan bahwa jumlah mahasiswa yang ada di Prodi Pendidikan Fisika semester 2 untuk angkatan 2020/2021 berjumlah 19. Jumlah mahasiswa tersebut tidak semuanya berasal dari baground IPA saat SMA/SMK/MA. Oleh karenanya beberapa mahasiswa tersebut tentu belum terbiasa dengan kegiatan perkuliahan yang menuntut adanya KPS di dalamnya. Secara karakteristik dalam mata kuliah sudah sangat jelas bahwa KPS dibutuhkan dan perlu untuk ditumbuh kembangkan dalam rangka mengembangkan pengetahuan untuk menemukan dan meningkatkan pemahaman mahasiswa dalam setiap kegiatan perkuliahan yang dilakukan.

Beberapa penelitian telah menerapkan KPS pada pembelajaran diantaranya: pada jenjang sekolah dasar (Eliyana, 2020; Lusidawaty et al., 2020; Sari \& Zulfadewina, 2018; Utama, 2019), pada jenjang sekolah menengah pertama dan sekolah menengah atas (Maharani et al., 2017; Muliyani et al., 2017) dan pada jenjang pendidikan tinggi melalui mata kuliah elektronika (Hadiya, 2018), termodinamika (Darmaji et al., 2018; Hasyim, 2018; Rohman \& Lusiyana, 2017), eksperimen (Maiyena \& Haris, 2017) dan fisika dasar 1 (Misbah, Mustikawati, M. Feyzarrif'at, 2018). Pada penelitian ini juga diterapkan pada jenjang Pendidikan tinggi, namun mata kuliah yang diterapkan pada fisika dasar 2 materi optika.

\section{METODE}

Kegiatan penelitian ini dilakukan dengan menggunakan metode deskriptif kuantitatif. Pada prosesnya penelitian ini diharapkan akan menghasilkan data yang akan dianalisis secara deskriptif dan akan diukur secara kategorikal. Adapun tempat penelitian yang digunakan yakni di STKIP Nurul Huda Sukaraja OKU Timur. Tes KPS dilaksanakan pada perkuliahan semester genap tahun akademik 2020/2021.

Semua mahasiswa Program Studi Pendidikan Fisika semester VI Tahun Akademik 2020/2021 dipilih sebagai sampel melalui Teknik cluster random sampling. Data penelitian yang nantinya berupa Skor KPS yang diambil dari hasil observasi pada saat perkuliahan mata kuliah Optik. Lembar Observasi yang digunakan adalah lembar yang dikembangkan oleh TIM yang terdiri dari soal tes dan Lembar Observasi KPS yakni 20 butir pernyataan.

Data penelitian diinterpretasikan pada tabel 1.

Tabel 1. Interpretasi KPS

\begin{tabular}{cc}
\hline Nilai & Interpretasi \\
\hline $0<$ KPS $\leq 20$ & Sangat Kurang Baik \\
$20<$ KPS $\leq 40$ & Kurang Baik \\
$40<$ KPS $\leq 60$ & Cukup \\
$60<$ KPS $\leq 80$ & Baik \\
$80<$ KPS $\leq 100$ & Sangat Baik \\
\hline
\end{tabular}

\section{HASIL DAN PEMBAHASAN}

Pemberian Instrumen soal tes KPS ditujukan untuk mengetahui kemampuan KPS mahasiswa. Selain analisis terhadap nilai ratarata (mean), soal KPS juga dianalisis persentase pada tiap indikator KPS. Berdasarkan hasil tes (posttest) soal KPS, diperoleh nilai rata-rata persentase sebesar $84,10 \%$ dengan kategori KPS sangat baik. Secara lebih jelas persentase hasil tes soal KPS per indikator antara kelas eksperimen dan kelas kontrol ditunjukkan pada tabel 2.

Tabel 2. Hasil KPS

\begin{tabular}{|c|c|c|c|}
\hline Indikator & $\begin{array}{c}\text { Nomor } \\
\text { Soal }\end{array}$ & $\%$ & Kategori \\
\hline Mengamati & 1,2 & 82,00 & $\begin{array}{c}\text { Sangat } \\
\text { Baik }\end{array}$ \\
\hline Mengelompokkan & 3 & 90,57 & $\begin{array}{l}\text { Sangat } \\
\text { baik }\end{array}$ \\
\hline Menginterpretasi & $4,5,6$ & 76,00 & Baik \\
\hline Memprediksi & 7,8 & 74,86 & Baik \\
\hline $\begin{array}{l}\text { Merancang } \\
\text { Percobaan }\end{array}$ & $9,10,11$ & 79,14 & Baik \\
\hline
\end{tabular}


Effendi, Arini Rosa Sinensis, Widayanti dan Thoha Firdaus

\begin{tabular}{|c|c|c|c|}
\hline Indikator & $\begin{array}{l}\text { Nomor } \\
\text { Soal }\end{array}$ & $\%$ & Kategori \\
\hline $\begin{array}{l}\text { Menerapkan } \\
\text { Konsep }\end{array}$ & $12,13,14$ & 78,19 & Baik \\
\hline $\begin{array}{l}\text { Mengajukan } \\
\text { Pertanyaan }\end{array}$ & 15 & 87,17 & $\begin{array}{c}\text { Sangat } \\
\text { Baik }\end{array}$ \\
\hline Berhipotesis & 16 & 82,00 & $\begin{array}{l}\text { Sangat } \\
\text { Baik }\end{array}$ \\
\hline $\begin{array}{l}\text { Menggunakan Alat } \\
\text { dan Bahan }\end{array}$ & 17,18 & 94,86 & $\begin{array}{l}\text { Sangat } \\
\text { Baik }\end{array}$ \\
\hline Mengkomunikasikan & 19,20 & 86,29 & $\begin{array}{l}\text { Sangat } \\
\text { Baik }\end{array}$ \\
\hline Jumlah & & 841.08 & Sangat \\
\hline Rata - rata & & 84.108 & Baik \\
\hline
\end{tabular}

KPS pada tabel 2 di uraikan sebagai berikut:

\section{Mengamati}

Mengamati merupakan KPS yang mendasar. Dalam keterampilan proses mengamati mahasiswa harus mampu menggunakan indra untuk mengumpulkan informasi (fakta) terhadap suatu objek atau peristiwa. Berdasarkan hasil persentase tes soal KPS pada indikator mengamati diperoleh nilai rata-rata persentase sebesar $82,00 \%$, Nilai rata-rata persentase KPS pada indikator mengamati tersebut dikategorikan baik. Pengamatan Langkah awal dalam meningkatkan KPS. Pengamatan yang baik akan memperoleh hasil KPS yang baik. Bahkan beberapa peneliti menyatakan bahwa pengamatan yang baik berpotensi untuk mengarahkan temuan yang baru dalam suatu eksperimen (Eliyana, 2020; Utama, 2019).

\section{Mengelompokkan}

Pada KPS mengelompokkan, mahasiswa harus dapat mengidentifikasi objek berdasarkan karakteristik masing-masing (persamaan dan perbedaan, kriteria, karakter) berdasarkan hasil proses mengamati. Berdasarkan hasil persentase tes soal KPS pada indikator mengelompokkan, mahasiswa pendidikan fisika memperoleh nilai rata-rata persentase sebesar $90,57 \%$. Nilai rata - rata persentase KPS pada indikator mengelompokkan tersebut dikategorikan sangat baik.

Mampu mengelompokkan Langkah awal untuk dapat menginterpretasi suatu masalah yang dihadapi. Kemampuan mengelompokkan yang dimiliki mahasiswa fisika kategori sangat baik, artinya mahasiswa berpotensi untuk dapat menginterpretasi data secara tepat.

\section{Menginterpretasi}

Pada KPS mengintepretasi mahasiswa ditujukan untuk dapat memahami data hasil dari suatu praktikum, mengidentifikasi hubungan antar variabel dari grafik/tabel yang diperoleh dari hasil suatu praktikum, serta kemampuan dalam menarik kesimpulan dari data hasil praktikum. Berdasarkan hasil persentase tes soal KPS pada indikator menginterpretasi, pada kelas pendidikan fisika diperoleh nilai rata - rata persentase sebesar $76,29 \%$. Nilai rata - rata persentase KPS pada indikator menginterpretasi dari kelas tersebut dikategorikan baik.

\section{Memprediksi}

KPS pada indikator memprediksi ditujukan agar mahasiswa dapat menggunakan fakta - fakta untuk merumuskan atau memperkirakan urutan kejadian atau urutan proses selanjutnya berdasarkan informasi yang telah diperoleh dari kegiatan pengamatan sebelumnya atau berdasarkan sumber yang terpercaya lainnya. Berdasarkan hasil persentase tes soal KPS pada indikator memprediksi, pada kelas pendidikan fisika diperoleh nilai rata - rata persentase sebesar $74,86 \%$. Nilai rata - rata persentase KPS pada indikator memprediksi tersebut dikategorikan baik.

\section{Merancang Percobaan}

KPS pada indikator merancang percobaan adalah KPS yang ditujukan agar mahasiswa dapat menentukan alat dan bahan yang digunakan dalam suatu praktikum secara tepat, dapat menentukan apa saja yang diamati, diukur, dan dicatat di dalam kegiatan praktikum, dapat menentukan cara dan langkah kerja di dalam suatu kegiatan praktikum, serta dapat menentukan cara mengolah data. Berdasarkan hasil persentase tes soal KPS pada indikator merancang percobaan, diperoleh nilai rata - rata persentase sebesar $79,14 \%$.

\section{Menerapkan Konsep}

KPS dengan indikator menerapkan 
konsep adalah KPS yang bertujuan agar mahasiswa dapat menggunakan konsep fisika dalam situasi, keadaan, peristiwa baru yang masih berkaitan dengan kegiatan praktikum terkait, serta bertujuan agar mahasiswa dapat menjelaskan data hasil praktikum atau hal - hal yang berkaitan dengan hasil kegiatan praktikum dengan menggunakan konsep fisika secara tepat. Berdasarkan hasil persentase tes soal KPS pada indikator menerapkan konsep diperoleh nilai rata - rata persentase sebesar $78,19 \%$.

\section{Mengajukan Pertanyaan}

KPS dengan indikator mengajukan pertanyaan adalah KPS yang ditujukan agar mahasiswa dapat mengajukan pertanyaan rumusan masalah terhadap suatu peristiwa atau objek pengamatan dalam suatu kegiatan praktikum, serta ditujukan agar mahasiswa dapat bertanya mengenai hal - hal yang belum diketahui yang berkaitan dengan hasil kegiatan praktikum. Berdasarkan hasil persentase tes soal KPS pada indikator mengajukan pertanyaan, diperoleh nilai rata - rata persentase sebesar $87,17 \%$.

\section{Berhipotesis}

KPS dengan indikator berhipotesis adalah KPS yang bertujuan agar mahasiswa dapat menyusun pernyataan (jawaban sementara) berdasarkan rumusan masalah yang menyatakan hasil yang diharapkan dari kegiatan praktikum berdasarkan buku atau sumber terpercaya lainnya. Berdasarkan hasil persentase tes soal KPS pada indikator berhipotesis diperoleh nilai rata - rata persentase sebesar $82,00 \%$.

\section{Menggunakan Alat dan Bahan}

KPS dengan indikator menggunakan alat dan bahan adalah KPS yang ditujukan agar mahasiswa dapat menggunakan alat dan bahan dengan benar dan tepat dalam suatu kegiatan praktikum, dapat menggunakan alat dan bahan secara berurutan berdasarkan langkah kerja, serta dapat mengetahui fungsi dan cara penggunaan masing - masing alat dan bahan dalam suatu kegiatan praktikum. Berdasarkan hasil persentase tes soal KPS pada indikator menggunakan alat dan bahan diperoleh nilai rata - rata persentase sebesar $94,86 \%$ dengan kategori sangat baik.

\section{Mengkomunikasikan}

Keterampilan proses sains dengan indikator mengkomunikasikan adalah KPS yang bertujuan agar mahasiswa dapat mengubah data hasil suatu kegiatan praktikum dalam bentuk lain, seperti grafik, tabel, atau diagram. Selain itu KPS kategori mengkomunikasikan ditujukan agar mahasiswa dapat membaca data hasil praktikum dari grafik, tabel, atau diagram, serta dapat menjelaskan atau menyampaikan hasil praktikum secara jelas dan sistematis. KPS pada indikator mengkomunikasikan juga bertujuan agar mahasiswa dapat menyimpulkan hasil praktikum berdasarkan data yang diperoleh dan berdasarkan grafik, tabel, atau diagram dengan tepat. Berdasarkan hasil persentase tes soal KPS pada indikator mengkomunikasikan diperoleh nilai rata - rata persentase sebesar $86,29 \%$ dengan kategori sangat baik.

Pada penelitian yang telah dilakukan menginterpretasi, memprediksi, merancang percobaan dan menerapkan konsep memiliki KPS yang lebih rendah daripada yang lain. Hal ini karena background mahasiswa fisika yang berbeda menyebabkan mahasiswa sulit untuk menginterpretasi data, kesulitan tersebut menyebabkan mahasiswa juga terkendala dalam memprediksi, merancang percobaan, dan menerapkan konsep. Namun, dengan kemampuan mengamati dan mengelompokkan yang sangat baik mahasiswa terus mengajukan pertanyaan hingga dapat berhipotesis secara tepat dan menggunakan alat dengan baik. Kemudian mahasiswa mampu mengomunikasikan dihadapan teman sejawat sehingga KPS yang dimiliki mahasiswa mengalami peningkatan.

Penemuan penelitian ini mendukung beberapa peneliti sebelumnya bahwa KPS dapat ditingkatkan melalui berbagai model dalam pembelajaran (Fathimah Zahrah, Abdul Halim, 2017; Susilawati et al., 2015; Utama, 2019). KPS sangat perlu diterapkan pada pembelajaran di semua jenjang Pendidikan. Karena pemahaman pada proses 
pembelajaran dapat diterapkan dalam kehidupan sehari-hari.

\section{PENUTUP}

Berdasarkan data hasil penelitian dan pembahasan yang dilakukan dapat disimpulkan bahwa hasil persentase KPS secara keseluruhan mahasiswa pendidikan fisika STKIP Nurul Huda pada Mata Kuliah Optika memperoleh nilai rata - rata persentase yang tinggi yakni sebesar $84,10 \%$ dengan kategori KPS sangat baik. Hal ini mengindikasikan bahwa mahasiswa program studi pendidikan fisika pada mata kuliah optika sudah memiliki keterampilan proses yang baik guna melakukan aktivitas - aktivitas yang berkaitan dengan sains.

\section{UCAPAN TERIMAKASIH}

Terima Kasih kepada LPPM STKIP Nurul Huda yang telah memberikan dana penelitian melalui hibah internal STKIP Nurul Huda dengan nomor kontrak 034/STKIP. NH/LPPM/II/2021.

\section{REFERENSI}

Artayasa, I. P., Susilo, H., Lestari, U., \& Indriwati, S. E. (2017). Profil keterampilan proses sains dan hubungannya dengan hasil belajar sains mahasiswa Pendidikan Guru Sekolah Dasar. Seminar Nasional Teknologi Pembelajaran Dan Pendidikan Dasar 2017, 706-714.

Darmaji, D., Kurniawan, D. A., Parasdila, H., \& Irdianti, I. (2018). Deskripsi Keterampilan Proses Sains Mahasiswa pada Materi Termodinamika. Berkala IImiah Pendidikan Fisika, 6(3), 345. https://doi.org/10.20527/bipf.v6i3.5290

Eliyana, E. (2020). Analisis Keterampilan Proses Sains Siswa Belajar IPA Materi Tumbuhan Hijau pada Siswa Kelas V SDN 3 Panjerejo Di Masa Pandemi Covid 19. Eduproxima, 2(2), 87-100.

Fathimah Zahrah, Abdul Halim, M. H. (2017). Penerapan Praktikum dengan Model Problem Based Learning (PBL) Pada Materi Laju Reaksi di Sma Negeri 1 Lembah Selawah. Jurnal Pendidikan
Sains Indonesia, 05(02), 117-126. http://jurnal.unsyiah.ac.id/jpsi

Firdaus, T., \& Sinensis, A. R. (2017). Keterampilan Dasar Kinerja IImiah pada Mahasiswa Calon Guru Fisika. Jurnal Pendidikan Fisika, 5(2), 102-110.

Hadiya, I. (2018). Analisis Keterampilan Proses Sains Mahasiswa Pendidikan Fisiska Dalam Merangkai Rangkaian Elektronika Sederhana. Relativitas, 1(1), 9-22.

Hasyim, F. (2018). Mengukur Kemampuan Berpikir Analitis dan Keterampilan Proses Sains Mahasiswa Calon Guru Fisika STKIP Al Hikmah Surabaya. JIPVA (Jurnal Pendidikan IPA Veteran), 2(1), 80. https://doi.org/10.31331/jipva.v2i1.591

Lusidawaty, V., Fitria, Y., MMiaz, Y., \& Zikri, A. (2020). Pembelajaran IPA dengan Strategi Pembelajaran Inkuiri untuk Meningkatkan Keterampilan Proses Sains dan Motivasi Belajar Siswa Di Sekolah Dasar. Jurnal Basicedu, 4(1), 168-174.

Maharani, M., Wati, M., \& Hartini, S. (2017). Pengembangan Alat Peraga pada Materi Usaha dan Energi untuk Melatihkan Keterampilan Proses Sains melalui Model Inquiry Discovery Learning (IDL) Terbimbing. Berkala Ilmiah Pendidikan Fisika, 5(3), 351-367.

Maiyena, S., \& Haris, V. (2017). Praktikalitas Video Tutorial pada Matakuliah Eksperimen Fisika untuk Meningkatkan Keterampilan Proses Sains Mahasiswa. Jurnal IImiah Pendidikan Fisika Al-Biruni, 6(1), 75. https://doi.org /10. 24042 /jpifalbiruni.v6i1.647

Misbah, Mustikawati, M. Feyzarrif'at, M. D. P. (2018). Pengembangan Penunjuk Praktikum Fisika dasar I Berbasis 5M untuk Melatih Keterampilan Proses sains dan karakter WASAKA. Jurnal Fisika FLUX, 15(1), 26-29.

Muliyani, R., Kurniawan, Y., \& Sandra, D. A. (2017). Peningkatan Keterampilan Proses Sains Terpadu Siswa melalui Implementasi Levels of Inquiry (Lol). Tadris: Jurnal Keguruan Dan IImu Tarbiyah, $\quad$ 02(2), 81-86. https://doi.org/10.24042/tadris.v2i2.1904

Rohman, F., \& Lusiyana, A. (2017). Pengembangan Modul Praktikum Mandiri Sebagai Asesmen Keterampilan Proses 
Sains dan Keterampilan Sosial Mahasiswa. JIPFRI: Jurnal Inovasi Pendidikan Fisika Dan Riset IImiah, 1(2), 47-56.

Sari, P. M., \& Zulfadewina. (2018). Profil Penguasaan keterampilan Proses Sains Mahasiswa program Studi Pendidikan Guru Sekolah dasar. Jurnal Inovasi Pendidikan Dasar, 3(2), 65-72.

Susilawati, Susilawati, \& Sridana, N. (2015). Pengaruh Model Pembelajaran Inkuiri Terbimbing Terhadap Keterampilan Proses Sains Siswa. Jurnal Tadris IPA Biologi FITK IAIN Mataram, 8(1), 27-36.

Utama, E. G. (2019). Pengaruh Model Pembelajaran POE (Predict, Observe and Explain) Terhadap Keterampilan Proses Sains Siswa SD Kelas V ditinjau dari Keterampilan Metakognitif. Jurnal Pendidikan Dasar Indonesia, 4(2), 46-52.

Widayanti, Yuberti, Irwandani, \& Hamid, A. (2018). Pengembangan Lembar Kerja Praktikum Percobaan Melde Berbasis Project Based Learning. Jurnal Pendidikan Sains Indonesia, 06(01), 2431. https://doi.org/10 .24815/jps i.v6i1 .10908 